\title{
Non-Penetrating Femtosecond Laser Intrastromal Astigmatic Keratotomy Performed during Laser-Assisted Cataract Surgery: Results on Keratometric Astigmatism
}

\author{
Anna Kaczmarek ${ }^{1}$, Claudia Brockmann ${ }^{1}$, Thomas Laube ${ }^{1,2 *}$ \\ ${ }^{1}$ Centre for Ophthalmology Düsseldorf, Düsseldorf, Germany \\ ${ }^{2}$ Department of Ophthalmology, University Hospital, University of Duisburg-Essen, Essen, Germany \\ Email: ^thomas.laube@zentrum-augenheilkunde.de
}

How to cite this paper: Kaczmarek, A., Brockmann, C. and Laube, T. (2017) Non-Penetrating Femtosecond Laser Intrastromal Astigmatic Keratotomy Performed during Laser-Assisted Cataract Surgery: Results on Keratometric Astigmatism. Open Journal of Ophthalmology, 7, 262-272. https://doi.org/10.4236/ojoph.2017.74035

Received: August 7, 2017

Accepted: October 28, 2017

Published: October 31, 2017

Copyright $\odot 2017$ by authors and Scientific Research Publishing Inc. This work is licensed under the Creative Commons Attribution International License (CC BY 4.0).

http://creativecommons.org/licenses/by/4.0/

\begin{abstract}
Purpose: To investigate the efficacy of non-penetrating femtosecond laser intrastromal astigmatic keratotomy (ISAK) in terms of topographic and refractive changes. Methods: Retrospective study including 42 eyes (35 patients) with a corneal astigmatism between 0.5 and $1.5 \mathrm{D}$. All eyes underwent femtosecond laser-assisted cataract surgery with ISAK for astigmatism management using the Catalys laser system (Johnson \& Johnson Vision). Visual acuity, refraction, as well as corneal topographic and corneal endothelial cell density (ECD) changes were evaluated during a 12-month follow-up. Astigmatic changes were analyzed using the Alpins vector method. Results: A significant reduction in manifest cylinder was observed at 1 month postoperatively $(\mathrm{p}=$ $0.03)$, with no significant changes afterwards $(p=0.90)$. A total of $38.1 \%$, $52.4 \%$ and $59.2 \%$ of eyes had a manifest cylinder of $0.50 \mathrm{D}$ or lower preoperatively and at 1 and 12 months after surgery, respectively. A significant reduction was found in topographic astigmatism at 1 month postoperatively $(\mathrm{p}<$ 0.01 ), with an additionally small but statistically significant reduction afterwards $(\mathrm{p}<0.01)$. No significant changes in postoperative uncorrected $(\mathrm{p}=$ $0.97)$ and corrected visual acuities $(\mathrm{p}=0.40)$ were observed during the follow-up. There was a trend to undercorrection of corneal astigmatism that decreased significantly over time. This led to some variability in changes of refractive astigmatism. A small but significant reduction in ECD was observed at 1 month postoperatively ( $\mathrm{p}<0.01$ ), with no significant changes afterwards. Conclusions: Femtosecond laser assisted ISAK is an effective and safe option to reduce corneal astigmatism during cataract surgery and consequently refractive astigmatism.
\end{abstract}




\section{Keywords}

Intrastromal Astigmatic Keratotomy, ISAK, Corneal Astigmatism, Cataract Surgery

\section{Introduction}

The use of femtosecond laser in cataract surgery has become a common practice in cataract surgery to perform several steps of the surgical procedure: anterior capsulotomy, lens segmentation, and creation of corneal incisions [1]. It has been demonstrated that femtosecond lasers are able to generate clear corneal incisions (CCI) with minimal associated changes of anterior and posterior corneal topography, and comparable with those of single-plane angled manual incision [2] [3]. Likewise, femtosecond laser incisions have shown to be stable, with minimal change in higher order aberrations (HOA) [4] [5] [6]. Furthermore, the femtosecond laser procedure for performing the corneal incision has been shown to be safe, efficient, and less damaging than the manual technique, as evidenced by lower central endothelial cell loss, lower increase of corneal thickness at the incision site and better tunnel morphology compared to the manual technique [7].

Besides the creation of astigmatic corneal incisions in cataract surgery, femtosecond lasers have been demonstrated to be useful for the performance of keratotomy in different types of corneas, inducing significant reduction of corneal astigmatism [8]-[19]. Day and Stevens [20] found that corneal biomechanical parameters and the astigmatism meridian were independent predictors of femtosecond laser intrastromal arcuate keratotomy efficacy. The aim of the current study was to further investigate the efficacy of non-penetrating femtosecond laser intrastromal astigmatic keratotomy (ISAK) in patients with a preoperative corneal astigmatism between 0.5 and $1.5 \mathrm{D}$, not only in terms of topographic changes, but also in terms of visual and refractive changes.

\section{Patients and Methods}

\subsection{Patients}

Retrospective data from consecutive patients who underwent femtosecond laserassisted cataract surgery with non-penetrating femtosecond laser intrastromal astigmatic keratotomy (ISAK) for mild to moderate astigmatism management were analyzed. All surgeries were performed by the same experienced surgeon (TL) between September 2014 and June 2015 at the Centre for Ophthalmology Düsseldorf. The study was performed in accordance with the Declaration of Helsinki and approved by the local Ethics Committee. Written consent for data processing was obtained from all patients.

\subsection{Inclusion and Exclusion Criteria}

From 337 patients undergoing femtosecond laser-assisted cataract surgery be- 
tween September 2014 and June 2015 those patients with the following inclusion criteria were selected: Diagnosed cataract with best corrected visual acuities better than $0.20 \operatorname{logMAR}(20 / 32)$, a preoperative corneal cylinder between 0.5 to 1.5 D (measured with Pentacam HR, Oculus Optikgeräte $\mathrm{GmbH}$ ), a total corneal irregular astigmatism (TCIA) below $0.300 \mu \mathrm{m}$, and ISAK treatment during femtosecond laser-assisted cataract surgery.

Exclusion criteria were: Corneal pathologies (e.g. scars, corneal thickness below $480 \mu \mathrm{m}$ ), a corneal endothelial cell density below $2000 / \mathrm{mm}^{2}$, a width of dilated pupils below $6 \mathrm{~mm}$ or retinal pathologies (e.g. diabetic retinopathy, macular degeneration).

\subsection{Preoperative and Postoperative Examinations}

All patients underwent a preoperative examination that included ocular biometry (IOLMaster, Carl Zeiss Meditec AG), objective refraction (Nidek AR 660-A), subjective refraction, noncontact tonometry (NT 530P, Oculus Optikgeräte $\mathrm{GmbH}$ ), anterior and posterior corneal topography and pachymetry (Pentacam HR), analysis of corneal endothelial cell density (EM 3000, Tomey), slit-lamp evaluation, measurement of maximal dilated pupil width (Colvard pupilometer, Oasis), and dilated funduscopy. IOL power calculation was performed using the IOLMaster and the Haigis formula based on the measurements of axial length, anterior chamber depth, and corneal radii.

Follow-up data at 1, 3, 6, and 12 months postoperatively were analyzed. Objective refraction, uncorrected visual acuity (UDVA), best corrected visual acuity (CDVA), corneal topography (Pentacam HR), and corneal endothelial cell density were recorded. Corneal topography measurements were used to compare the pre- and postoperative astigmatism. Manifest cylinder was compared between pre- and postoperative examinations.

\subsection{Surgical Procedure}

All patients were informed about possible intraoperative and postoperative complications and written informed consent was obtained. After topical anesthesia with oxybuprocaine hydrochloride (Conjuncain EDO) and insertion of a lightweight lid speculum (Barraquer eye speculum, $43 \mathrm{~mm}$ ), the 0 and 180-degree axis were marked with a pendular marker (Gerten horizontal axis marker, Geuder AG) using a sterile disposable ink pen (Devon ${ }^{\mathrm{TM}}$ utility marker, Covidien) with the patient standing upright.

The surgical procedure was performed under peribulbar anesthesia (prilocainhydrochlorid and ropivacain, with added hyaluronidase) using the Catalys laser system (Johnson \& Johnson Vision; software version cOS 3.0). The programmed anterior capsulotomy size was $4.9 \mathrm{~mm}$ in all eyes and centered according to the scanned capsule. Crystalline lens fragmentation was performed using a standardized template (quadrants softened pattern). The lens fragmentation details included a segment-soft spacing of $350 \mu \mathrm{m}$ and a grid spacing of 600 
$\mu \mathrm{m}$ at a maximum diameter, and segmentation repetitions set at 4 .

Alignment of the docking interface to the previously marked cornea was done manually followed by the fine adjustment of the laser system integrated optical coherence tomographic (OCT) guidance that ensured the placement of the intrastromal astigmatic keratotomies $(\mathrm{AK})$ at the required corneal meridian. This step was supported by the clear visibility of the ink marking in the OCT.

The nomogram according to Stevens (2015; v3) was used for intrastromal AKs. (Stevens J. Intrastromal AK nomogram calculator v3 2015. Available at http://www.femtoemulsification.com/.) All intrastromal AKs were 8.0-mm diameter paired symmetrical arcs and were centered according to the scanned capsule. The arcs were programmed to be intrastromal, nonpenetrating, with a depth between $20 \%$ and $80 \%$ of corneal pachymetry as measured by the laser system integrated OCT. Further intrastromal AK parameters were: 90-degree side-cut angle, horizontal and vertical spot spacing of $5 \mu \mathrm{m}$ and $10 \mu \mathrm{m}$, respectively, pulse energy of $5 \mu \mathrm{J}$, anterior line density of 10 , anterior line distance of $30 \%$, and central line density of 4 .

Lens removal was performed with a standard phacoemulsification procedure using the Infiniti ${ }^{\circledR}$ Vision System (Alcon). A $2.2 \mathrm{~mm}$ clear corneal temporal incision and two $1.1 \mathrm{~mm}$ side ports were created using a disposable steel keratome.

\subsection{Statistical Analysis}

Statistical analyzes were performed with a commercially available software package (SPSS for Mac, Version 20.0; IBM Corporation, Armonk, NY, USA). Normality of data samples was evaluated by means of the Kolmogorov-Smirnov test. For the analysis of differences between preoperative and postoperative visits, the Student $t$ test for paired data or the Wilcoxon ranked sum test were used depending if the samples were distributed normally or not, respectively. For all statistical tests, a p-value of less than 0.05 was considered as statistically significant. Cross-checks were performed to exclude bias due to the inclusion of both eyes of some patients.

The Alpins vector analysis method was used for the analysis of the astigmatic changes occurring after surgery [21] [22]. The following vectors were determined and evaluated: targeted induced astigmatism (TIA) as the vector of intended change in cylinder for each treatment, surgically induced astigmatism (SIA) as the vector of the real change achieved and difference vector (DV) as the additional astigmatic change that would enable the initial surgery to achieve its intended target. Additionally, the magnitude of error (ME) (difference between the magnitude of SIA and TIA) and the angle of error (AE) (angle described by the vectors of SIA and TIA) were calculated.

\section{Results}

The whole sample included 35 patients that received femtosecond laser-assisted cataract surgery combined with ISAK. Table 1 shows details of the demographic 
Table 1. Demographic and clinical characteristics of the study group.

\begin{tabular}{cc}
\hline \multicolumn{2}{c}{ Patient characteristics } \\
\hline No. of study eyes & 42 (22 right eyes, 20 left eyes $)$ \\
Patient gender & 16 males, 19 females \\
& Mean \pm SD: $71.5 \pm 6.7$ \\
Age (years) & Median: 72 \\
& Range: 59 - 86 \\
Central corneal thickness $(\mu \mathrm{m})$ & Mean \pm SD: $563.4 \pm 33.3$ \\
& Median: 568 \\
& Range: $495-626$
\end{tabular}

Abbreviation: SD, standard deviation.

and clinical characteristics of the study group. The mean preoperative and postoperative data are summarized in Table 2. As shown, no significant changes were detected in sphere $(p \geq 0.57)$ and spherical equivalent $(p \geq 0.48)$ during the entire follow-up. In contrast, there was a significant reduction in manifest cylinder at 1 month postoperatively $(p=0.03)$, with no significant changes afterwards $(p=0.90)$. This was consistent with the presence of a less scattered distribution of postoperative manifest astigmatism compared to the preoperative distribution (Figure 1). A total of $38.1 \%$ (16/42) of eyes had a preoperative manifest cylinder of $0.50 \mathrm{D}$ or lower, whereas this percentage increased to $52.4 \%(22 / 42)$ at 1 month postoperatively and $59.2 \%(25 / 42)$ at 12 months postoperatively. In agreement with refractive astigmatic changes, a significant reduction was found in topographic astigmatism at 1 month postoperatively $(\mathrm{p}<0.01$ ), with an additional small but statistically significant reduction during the remaining follow-up ( $\mathrm{p}<0.01$ ) (Figure 2) (Table 2). Regarding visual acuity outcomes, no significant changes in postoperative UDVA $(\mathrm{p}=0.97)$ and CDVA $(\mathrm{p}=0.40)$ were observed during the follow-up.

Table 3 summarizes the outcomes of the vector analysis of changes in manifest and corneal astigmatism. As shown, there was a trend to undercorrection of corneal astigmatism that decreased significantly over time (increase of SIA $\mathrm{p}<$ 0.01 , decrease of DV $p=0.04$, less negative ME $p=0.04$ ). This led to some variability in the changes of refractive astigmatism, with no significant changes in the vector parameters during the follow-up ( $p \geq 0.41)$.

Concerning endothelial cell density (ECD) changes, a small but statistically significant reduction was observed at 1 month postoperatively $(\mathrm{p}<0.01)$. However, no significant changes were found in ECD during the remaining follow-up $(\mathrm{p}=0.09)$.

\section{Discussion}

In the current study, we have demonstrated that non-penetrating femtosecond laser-assisted ISAK is effective not only in terms of corneal topographic 
Table 2. Summary of the preoperative and postoperative data obtained in the analyzed sample.

\begin{tabular}{|c|c|c|c|c|c|c|c|}
\hline $\begin{array}{c}\text { Mean (SD) } \\
\text { Median (Range) }\end{array}$ & Preoperative & $\begin{array}{l}1 \text { month } \\
\text { postoperative }\end{array}$ & $\begin{array}{c}3 \text { months } \\
\text { postoperative }\end{array}$ & $\begin{array}{c}6 \text { months } \\
\text { postoperative }\end{array}$ & $\begin{array}{c}12 \text { months } \\
\text { postoperative }\end{array}$ & $\begin{array}{l}\text { P-value } \\
\text { (preop-1 } \\
\text { month) }\end{array}$ & $\begin{array}{c}\text { P-value } \\
(1-12 \\
\text { months })\end{array}$ \\
\hline $\begin{array}{c}\text { Total corneal } \\
\text { irregular astigmatism } \\
(\mu \mathrm{m})\end{array}$ & $\begin{array}{c}0.16(0.05) \\
0.15(0.07 \text { to } 0.28)\end{array}$ & $\begin{array}{c}0.19(0.07) \\
0.18(0.09 \text { to } 0.34)\end{array}$ & $\begin{array}{c}0.18(0.07) \\
0.17(0.08 \text { to } 0.35)\end{array}$ & $\begin{array}{c}0.18(0.07) \\
0.16(0.07 \text { to } 0.37)\end{array}$ & $\begin{array}{c}0.19(0.06) \\
0.18(0.10 \text { to } 0.39)\end{array}$ & $<0.01$ & 0.44 \\
\hline $\begin{array}{c}\text { Endothelial cell } \\
\text { density (cell/mm²) }\end{array}$ & $\begin{array}{c}2529.7(298.5) \\
2488.5(2007 \text { to } 3575)\end{array}$ & $\begin{array}{c}2312.4(450.7) \\
2312.5(1363 \text { to } 3338)\end{array}$ & $\begin{array}{c}2380.3(394.6) \\
2417.5(1771 \text { to } 3298)\end{array}$ & $\begin{array}{c}2317.1(395.7) \\
2323.0(1566 \text { to } 3347)\end{array}$ & $\begin{array}{c}2379.7(368.7) \\
2378.0(1716 \text { to } 3333)\end{array}$ & $<0.01$ & 0.09 \\
\hline LogMAR UDVA & --- & $\begin{array}{c}0.13(0.15) \\
0.07(0.00 \text { to } 0.52)\end{array}$ & $\begin{array}{c}0.14(0.19) \\
0.05(0.00 \text { to } 0.70)\end{array}$ & $\begin{array}{c}0.13(0.17) \\
0.05(0.00 \text { to } 0.70)\end{array}$ & $\begin{array}{c}0.11(0.15) \\
0.02(-0.08 \text { to } 0.52)\end{array}$ & --- & 0.97 \\
\hline Sphere (D) & $\begin{array}{c}-0.54(3.72) \\
0.50(-9.00 \text { to } 8.00)\end{array}$ & $\begin{array}{c}-0.20(1.46) \\
0.25(-2.75 \text { to } 2.75)\end{array}$ & $\begin{array}{c}-0.28(1.41) \\
0.25(-2.75 \text { to } 2.00)\end{array}$ & $\begin{array}{c}-0.27(1.40) \\
0.25(-2.50 \text { to } 2.00)\end{array}$ & $\begin{array}{c}-0.21(1.37) \\
0.25(-2.75 \text { to } 2.00)\end{array}$ & 0.81 & 0.57 \\
\hline Cylinder (D) & $\begin{array}{c}-0.94(0.62) \\
-0.88(-2.50 \text { to } 0.00)\end{array}$ & $\begin{array}{c}-0.64(0.45) \\
-0.50(-1.75 \text { to } 0.00)\end{array}$ & $\begin{array}{c}-0.59(0.39) \\
-0.50(-1.75 \text { to } 0.00)\end{array}$ & $\begin{array}{c}-0.56(0.37) \\
-0.50(-1.75 \text { to } 0.00)\end{array}$ & $\begin{array}{c}-0.63(0.37) \\
-0.50(-1.75 \text { to } 0.00)\end{array}$ & 0.03 & 0.90 \\
\hline SE (D) & $\begin{array}{c}-1.01(3.73) \\
0.06(-9.25 \text { to } 7.50)\end{array}$ & $\begin{array}{c}-0.52(1.44) \\
0.00(-3.25 \text { to } 2.13)\end{array}$ & $\begin{array}{c}-0.58(1.44) \\
-0.13(-3.00 \text { to } 1.75)\end{array}$ & $\begin{array}{c}-0.55(1.43) \\
0.00(-2.88 \text { to } 1.75)\end{array}$ & $\begin{array}{c}-0.52(1.39) \\
0.00(-3.00 \text { to } 1.75)\end{array}$ & 0.69 & 0.48 \\
\hline LogMAR CDVA & --- & $\begin{array}{c}0.03(0.08) \\
0.00(-0.08 \text { to } 0.22)\end{array}$ & $\begin{array}{c}0.02(0.08) \\
0.00(-0.08 \text { to } 0.30)\end{array}$ & $\begin{array}{c}0.03(0.08) \\
0.00(-0.08 \text { to } 0.22)\end{array}$ & $\begin{array}{c}0.02(0.09) \\
0.00(-0.08 \text { to } 0.30)\end{array}$ & --- & 0.40 \\
\hline
\end{tabular}

Abbreviations: SD, standard deviation; D, dioptre; UDVA, uncorrected distance visual acuity; SE, spherical equivalent; CDVA, corrected distance visual acuity.

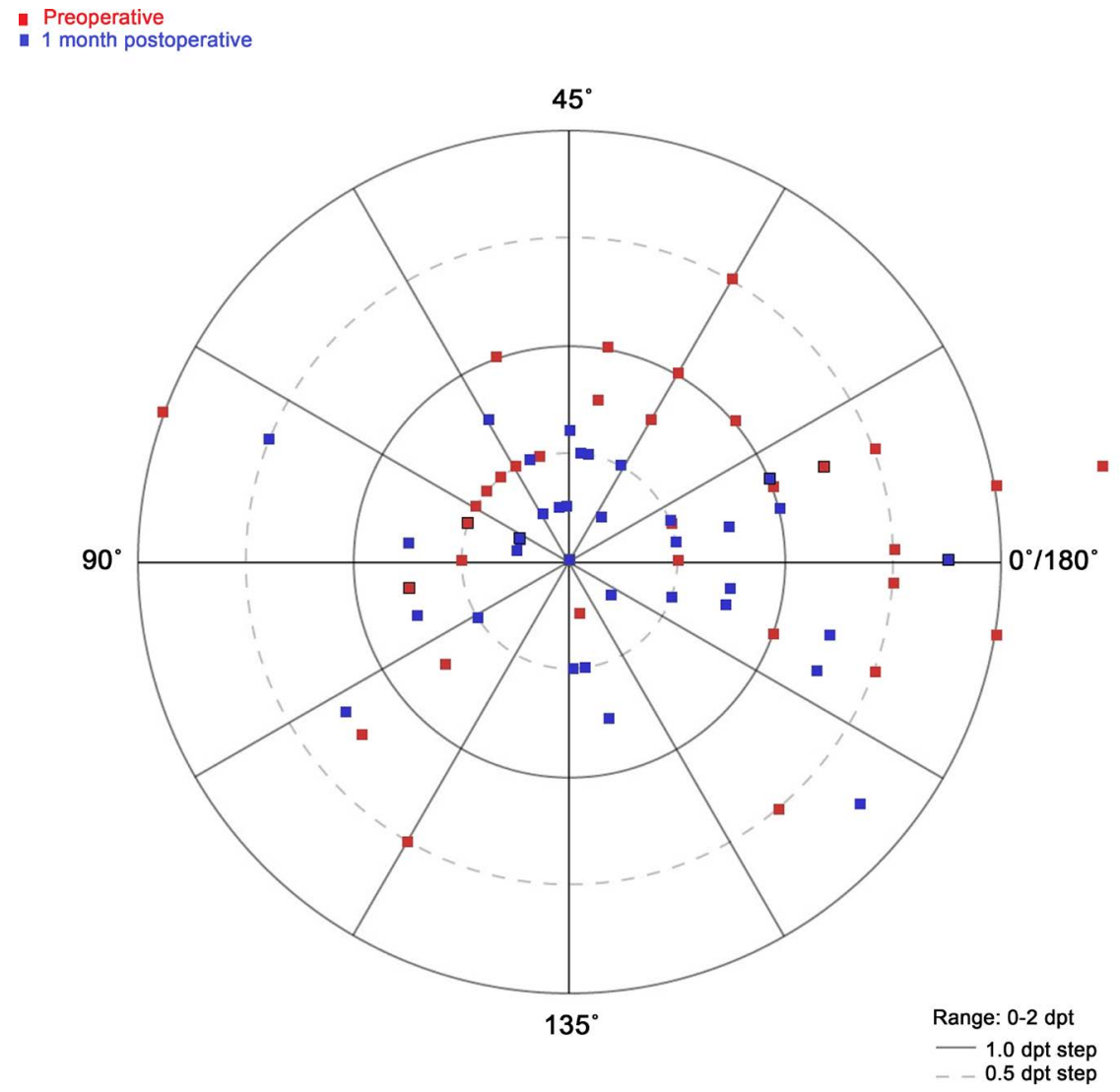

Figure 1. Polar plot showing the distribution of the preoperative (red dots) and 1 month postoperative (blue dots) manifest cylinder. 
I. Preoperative
1 month postoperative

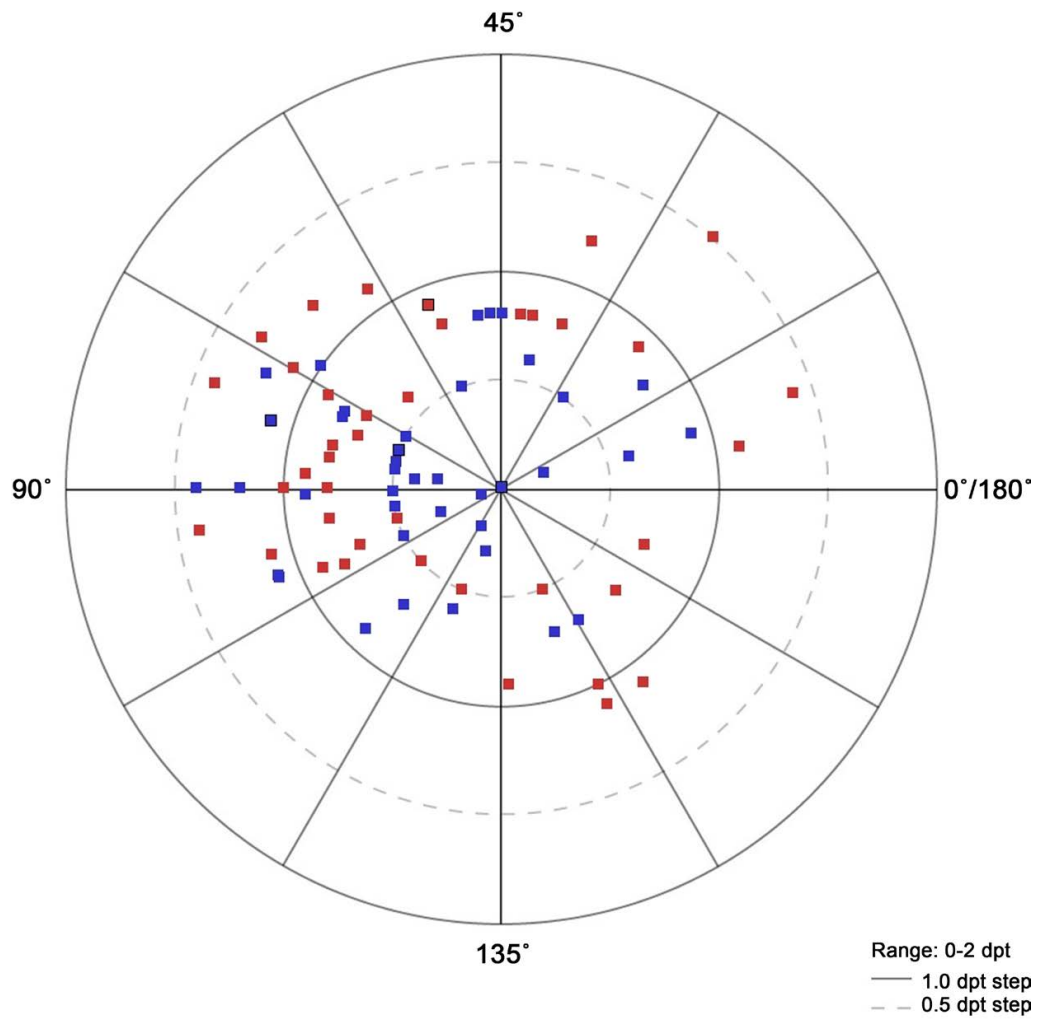

Figure 2. Polar plot showing the distribution of the preoperative (red dots) and 1 month postoperative (blue dots) corneal topographic cylinder.

Table 3. Summary of the vector analysis changes in manifest and corneal astigmatism in the analyzed sample.

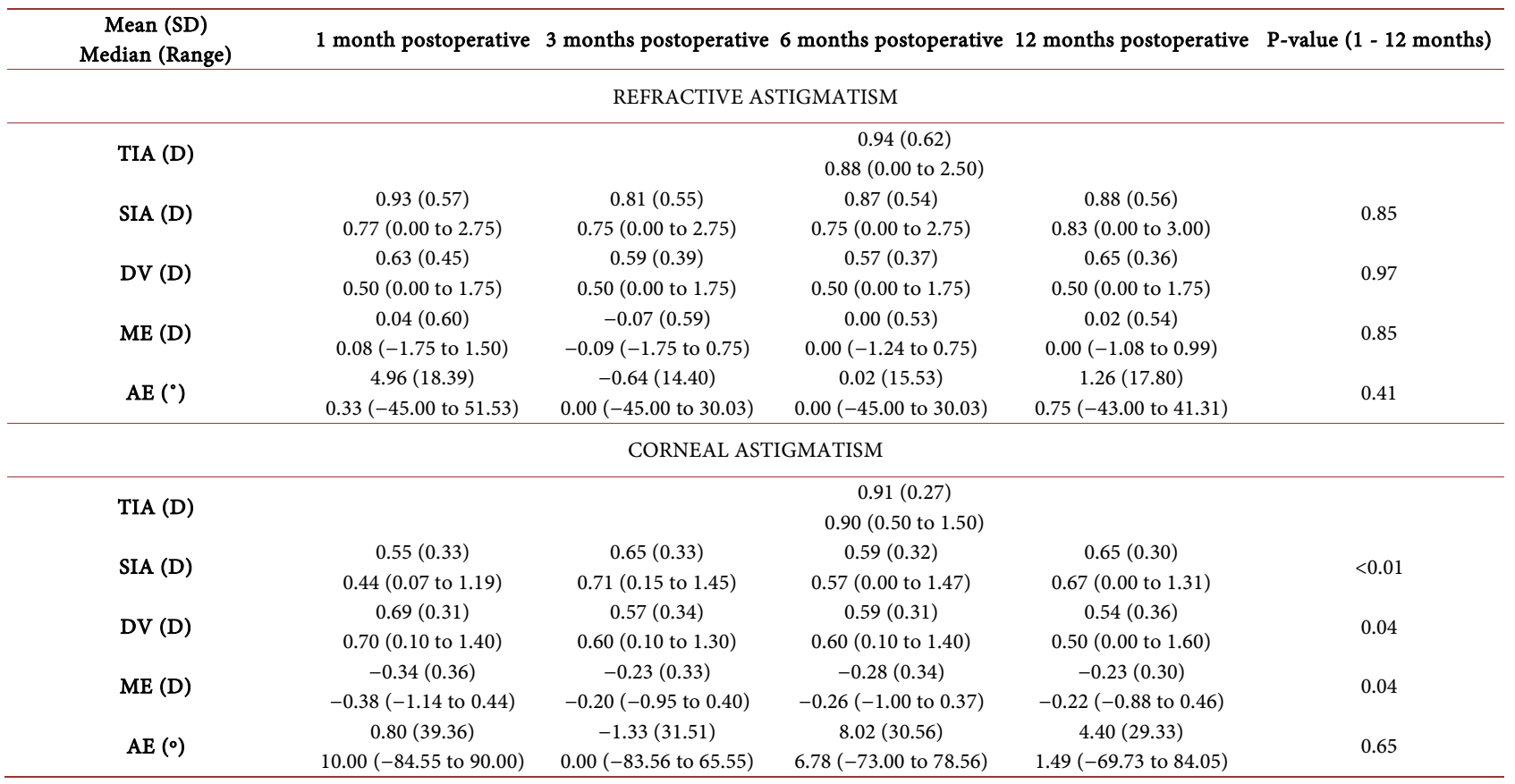

*Abbreviations: SD, standard deviation; D, dioptre; TIA, targeted induced astigmatism; SIA, surgically induced astigmatism; DV, difference vector; ME, magnitude of error; $\mathrm{AE}$, angle of error. 
astigmatism reduction, but also in terms of refractive astigmatic reduction. We included patients with a preoperative corneal astigmatism between 0.5 and 1.5 $D$; for eyes with higher corneal astigmatism we prefer to implant toric intraocular lenses. A significant reduction of the magnitude of refractive and corneal astigmatism was found in our series of healthy corneas after ISAK. This reduction of the magnitude of corneal astigmatism has been also reported by different authors not only in healthy eyes undergoing penetrating or non-penetrating femtosecond laser-assisted keratotomy [8] [11] [12] [13] [16], but also after refractive surgery [18] or even in post-keratoplasty corneas with high levels of associated astigmatism [9] [10] [14] [15]. Comparable to our study, Löffler et al. [8] have recently reported a reduction of the magnitude of anterior corneal astigmatism in a prospective study enrolling 27 healthy corneas undergoing penetrating femtosecond laser-assisted keratotomy, with minimal effect on the magnitude of posterior corneal astigmatism. Chan et al. [11] found in a retrospective study including 50 healthy corneas that had undergone single, $450-\mu \mathrm{m}$ deep, arcuate keratotomy paired at the $8-\mathrm{mm}$ zone that anterior corneal astigmatism decreased significantly from $1.35 \pm 0.48 \mathrm{D}$ preoperatively to $0.67 \pm 0.54 \mathrm{D}$ at 2 months and $0.74 \pm 0.53 \mathrm{D}$ at 2 years postoperatively. These authors found a relative stability of the astigmatic reduction over a 2-year follow-up [11]. In our series, we also found this trend in a 1-year follow-up, although the reduction at the end of the follow-up reached statistical significance in spite of its low magnitude. These results are in contrast to those reported by Day and Stevens [12], who found small but statistically significant regressions in SIA after ISAK between 1 and 6 months postoperatively. Differences in the nomogram used by these authors may account for this trend as well as differences in corneal biomechanics and astigmatism magnitude between samples.

The reduction in corneal topographic astigmatism was associated with a reduction in refractive cylinder, as observed in other studies evaluating the effect of femtosecond-assisted ISAK in virgin [13], post-refractive surgery [18], and post-keratoplasty corneas [9] [10] [15]. Day and colleagues [13] found in a prospective case series including 196 eyes undergoing femtosecond laser-assisted ISAK that $0 \%$ of the eyes had a refractive cylinder of $0.50 \mathrm{D}$ or less preoperatively, with an increase to $32.1 \%$ postoperatively. In our sample, better outcomes were obtained, with $38.1 \%$ and $52.4 \%$ of eyes having a manifest cylinder of 0.50 D or lower preoperatively and at 1 month after surgery, respectively. Possibly, the fact of including astigmatisms of lower magnitude in our series may have accounted for this finding as well as other factors. For example, corneal biomechanical parameters and the astigmatism meridian have been found to be independent predictors of femtosecond laser ISAK efficacy even after adjusting for AK arc length, AK start depth, and preoperative corneal cylinder [20]. Venter et al. [18] found in a sample of 112 eyes with previous refractive surgery that the mean absolute subjective cylinder decreased significantly from $1.20 \pm 0.47 \mathrm{D}$ preoperatively to $0.55 \pm 0.40 \mathrm{D}$ postoperatively. 
Changes in corneal and refractive astigmatism were also analyzed by vector analysis. This analysis revealed a trend to undercorrection, with a mean DV value of $0.57 \pm 0.34 \mathrm{D} 3$ months postoperatively. This trend has been also reported in previous studies [13] [16]. In our series, this trend to undercorrection was maintained during the 12-month follow-up. Similarly, Day and colleagues [13] found in a group of eyes undergoing ISAK a mean DV of $0.74 \pm 0.38 \mathrm{D}$ (range 0.00 to $2.25 \mathrm{D}$ ), with a mean corneal astigmatism correction of $63 \%$. It should be considered that although the first corneal surface is the main source of astigmatism in healthy eyes, there are also other sources of astigmatism, such as the posterior corneal surface or the crystalline lens. Therefore, a partial or variable correction of anterior corneal astigmatism may be acceptable. For this reason, we also performed a vector analysis but based on refractive astigmatism. This analysis also showed a trend to undercorrection, but with a higher level of variability, including some cases of predictable correction and some cases of overcorrection. This may be explained by the interaction of internal astigmatism with corneal astigmatic changes. It should be noted that no significant changes in DV, $\mathrm{ME}$ and $\mathrm{AE}$ were found during the 1-year follow-up, indicating that the refractive change induced by ISAK was stable. Thus, we consider the follow-up of 12 months as an adequate time to state the effectiveness of the ISAK treatment.

Finally, we evaluated the potential induction of endothelial changes with surgery. We obtained a low magnitude reduction in ECD, although statistically significant at 1 month postoperatively, with no additional changes afterwards. This endothelial change may be related to the surgical manipulation and not directly to the performance of the ISAK treatment. Indeed, other studies have reported no significant changes in ECD with femtosecond laser-assisted ISAK alone [19].

\section{Conclusion}

Femtosecond laser assisted ISAK is an effective and safe option to reduce corneal astigmatism during cataract surgery and consequently refractive astigmatism. This option does not induce a clinically significant corneal endothelial damage. The impact on refractive astigmatism is dependent on the interaction between internal and anterior corneal astigmatism after surgery.

\section{References}

[1] Nagy, Z.Z. and McAlinden, C. (2015) Femtosecond Laser Cataract Surgery. Eye Vis (London), 2, 11. https://doi.org/10.1186/s40662-015-0021-7

[2] Serrao, S., Lombardo, G., Schiano-Lomoriello, D., Ducoli, P., Rosati, M. and Lombardo, M. (2014) Effect of Femtosecond Laser-Created Clear Corneal Incision on Corneal Topography. Journal of Cataract \& Refractive Surgery, 40, 531-537. https://doi.org/10.1016/j.jcrs.2013.11.027

[3] Serrao, S., Lombardo, G., Ducoli, P., Rosati, M. and Lombardo, M. (2013) Evaluation of Femtosecond Laser Clear Corneal Incision: An Experimental Study. Journal of Refractive Surgery, 29, 418-424. https://doi.org/10.3928/1081597X-20130430-01

[4] Serrao, S., Lombardo, G., Schiano-Lomoriello, D., Rosati, M. and Lombardo, M. 
(2014) Preliminary Investigation of Corneal Wavefront Aberration Following Femtosecond Laser Clear Corneal Incision for Cataract Surgery. European Journal of Ophthalmology, 24, 842-849. https://doi.org/10.5301/ejo.5000485

[5] Nagy, Z.Z., Dunai, A., Kránitz, K., Takács, A.I., Sándor, G.L., Hécz, R. and Knorz, M.C. (2014) Evaluation of Femtosecond Laser-Assisted and Manual Clear Corneal Incisions and Their Effect on Surgically Induced Astigmatism and Higher-Order Aberrations. Journal of Refractive Surgery, 30, 522-525.

https://doi.org/10.3928/1081597X-20140711-04

[6] Alió, J.L., Abdou, A.A., Soria, F., Javaloy, J., Fernández-Buenaga, R., Nagy, Z.Z. and Filkorn, T. (2013) Femtosecond Laser Cataract Incision Morphology and Corneal Higher-Order Aberration Analysis. Journal of Refractive Surgery, 29, 590-595. https://doi.org/10.3928/1081597X-20130819-01

[7] Mastropasqua, L., Toto, L., Mastropasqua, A., Vecchiarino, L., Mastropasqua, R., Pedrotti, E. and Di Nicola, M. (2014) Femtosecond Laser Versus Manual Clear Corneal Incision in Cataract Surgery. Journal of Refractive Surgery, 30, 27-33. https://doi.org/10.3928/1081597X-20131217-03

[8] Löffler, F., Böhm, M., Herzog, M., Petermann, K. and Kohnen, T. (2017) Tomographic Analysis of Anterior, Posterior and Total Corneal Refractive Power Changes after Femtosecond Laser-Assisted Keratotomy. American Journal of Ophthalmology, 180, 102-109. https://doi.org/10.1016/j.ajo.2017.05.015

[9] Hashemian, M.N., Ojaghi, H., Mohammadpour, M., Jabbarvand, M., Rahimi, F., Abtahi, M.A., Mazloumi, M. and Abtahi, S.H. (2017) Femtosecond Laser Arcuate Keratotomy for the Correction of Postkeratoplasty High Astigmatism in Keratoconus. Journal of Research in Medical Sciences, 22, 17. https://doi.org/10.4103/1735-1995.200267

[10] Al Sabaani, N., Al Malki, S., Al Jindan, M., Al Assiri, A. and Al Swailem, S. (2016) Femtosecond Astigmatic Keratotomy for Postkeratoplasty Astigmatism. Saudi Journal of Ophthalmology, 30, 163-168. https://doi.org/10.1016/j.sjopt.2016.04.003

[11] Chan, T.C., Ng, A.L., Cheng, G.P., Wang, Z., Woo, V.C. and Jhanji, V. (2016) Corneal Astigmatism and Aberrations after Combined Femtosecond-Assisted Phacoemulsification and Arcuate Keratotomy: Two-Year Results. American Journal of Ophthalmology, 170, 83-90.

[12] Day, A.C. and Stevens, J.D. (2016) Stability of Keratometric Astigmatism after Non-Penetrating Femtosecond Laser Intrastromal Astigmatic Keratotomy Performed during Laser Cataract Surgery. Journal of Refractive Surgery, 32, 152-155. https://doi.org/10.3928/1081597X-20160204-01

[13] Day, A.C., Lau, N.M. and Stevens, J.D. (2016) Nonpenetrating Femtosecond Laser Intrastromal Astigmatic Keratotomy in Eyes Having Cataract Surgery. Journal of Cataract \& Refractive Surgery, 42, 102-109.

[14] Loriaut, P., Borderie, V.M. and Laroche, L. (2015) Femtosecond-Assisted Arcuate Keratotomy for the Correction of Postkeratoplasty Astigmatism: Vector Analysis and Accuracy of Laser Incisions. Cornea, 34, 1063-1066. https://doi.org/10.1097/ICO.0000000000000487

[15] Fadlallah, A., Mehanna, C., Saragoussi, J.J., Chelala, E., Amari, B. and Legeais, J.M. (2015) Safety and Efficacy of Femtosecond Laser-Assisted Arcuate Keratotomy to Treat Irregular Astigmatism after Penetrating Keratoplasty. Journal of Cataract \& Refractive Surgery, 41, 1168-1175.

[16] Chan, T.C., Cheng, G.P., Wang, Z., Tham, C.C., Woo, V.C. and Jhanji, V. (2015) Vector Analysis of Corneal Astigmatism after Combined Femtosecond-Assisted 
Phacoemulsification and Arcuate Keratotomy. American Journal of Ophthalmology, 160, 250-255.

[17] Kankariya, V.P., Diakonis, V.F., Goldberg, J.L., Kymionis, G.D. and Yoo, S.H. (2014) Femtosecond Laser-Assisted Astigmatic Keratotomy for Postoperative Trabeculectomy-Induced Corneal Astigmatism. Journal of Refractive Surgery, 30, 502-504. https://doi.org/10.3928/1081597X-20140527-01

[18] Venter, J., Blumenfeld, R., Schallhorn, S. and Pelouskova, M. (2013) Non-Penetrating Femtosecond Laser Intrastromal Astigmatic Keratotomy in Patients with Mixed Astigmatism after Previous Refractive Surgery. Journal of Refractive Surgery, 29, 180-186. https://doi.org/10.3928/1081597X-20130129-09

[19] Rückl, T., Dexl, A.K., Bachernegg, A., Reischl, V., Riha, W., Ruckhofer, J., Binder, P.S. and Grabner, G. (2013) Femtosecond Laser-Assisted Intrastromal Arcuate Keratotomy to Reduce Corneal Astigmatism. Journal of Cataract \& Refractive Surgery, 39, 528-538.

[20] Day, A.C. and Stevens, J.D. (2016) Predictors of Femtosecond Laser Intrastromal Astigmatic Keratotomy Efficacy for Astigmatism Management in Cataract Surgery. Journal of Cataract \& Refractive Surgery, 42, 251-257.

[21] Alpins, N.A. (1997) New Method of Targeting Vectors to Treat Astigmatism. Journal of Cataract \& Refractive Surgery, 23, 65-75.

[22] Alpins, N. (2001) Astigmatism Analysis by the Alpins Method. Journal of Cataract \& Refractive Surgery, 27, 31-49. 